\title{
CHAVE PROVISÓRIA PARA IDENTIFICAÇÃO DOS GENEROS DE ALGAS MARINHAS DA ZONA DAS MARÉS DO LITORAL DO ESTADO DE PERNAMBUCO
}

\author{
AYLTHON B. JOLY
}

Departamento de Botânica, Instituto de Biociências da Universidalle de São Paulo. Departamento de Botânica, Instituto de Biologia da Universidade Estadual de Campinas

- SONIA M. B. PEREIRA (*)

Laboratório de Ciências do Mar da Universidade Federal de Pernambuco

\section{SYNOPSIS}

Este trabalho apresenta uma chave dicotomica simplificada destinada ao uso de estudantes, como uma ajuda na identificação de 92 gêneros de algas marinhas da zona de marés, encontrados nos arredores e na região da cidade do Recife, Estado de Pernambuco.

Uma breve Introdução ajuda o principiante em como proceder para um melhor aproveitamento no uso da chave.

\section{INTRODUÇÃO}

Chaves dicotômicas de identificação são elaboradas com a finalidade de facilitar ao estudante encontrar o nome correto para designar esta ou aquela planta da área em estudo.

O estudante cuidadoso, manuseando esta chave mesmo sem a tutela de um professor, poderá rapidamente fazer progressos notáveis, pois uma vez achado um determinado nome, poderá ele então recorrer a um livro de referência e conferir as descrições e figuras que lá se encontram, com uma planta e assim a,primorar seus conhecimentos.

Somente desta forma, com a popularização do ensino, dando meios aos estudantes de encontrarem o que procuram, faz-se progresso no conhecimento global da flora de uma região.

(*) Bolsista do Conselho Nacional de Pesquisas.

Trab. Oceanogr. Univ. Fed. Pe., Recife, 13 271-282, 1972 
Temos necessidade urgente de facilitar o aprendizado da Taxonomia Vegetal no Brasil. O país ressente-se da falta de taxonomistas treinados, em todos os grupos de plantas. Uma das razões porque estamos nessa situação é justamente a falta de meios de treinar gente, de interessar estudantes promissores no conhecimento da flora de sua região.

Assim uma chave, mesmo provisória, como a presente, serve à sua finalidade primordial, de possibilitar treinamento de estudantes. Estes futuramente, tornarão a chave definitiva, acrescentando aquilo que agora falta e que por desconhecimento nosso no presente, não figura na chave. Essa falha entretanto representa apenas, segundo o que se pode esperar, talvez apenas $10 \%$ dos gêneros que ocorrem na área para a qual a presente chave foi elaborada.

\section{PROCEDIMENTO}

O estuciante deverá ter certos conhecimentos prévios de biologia e em particular de Botânica a fim de poder, sem dificuldade manusear a chave, pois certos termos técnicos, não puderam deixar de ser empregados, apesar do esforço feito para tornar a chave o mais acessivel possivel. Recomenda-se neste caso o uso de um Glossário ou Dicionário especializados em Botânica.

E indispensável o uso de um microscópio razoável, sem o que não será posșivel estudar algas. Estas deverão ser estudadas ao vivo sempre que isso não acarrete grandes problemas; caso isso seja impraticável, recomenda-se a flxação do material em solução de formol a 4\%, preparada com água do mar. Recomenda-se guardar o material, vivo ou fixado, ao abrigo da luz, até que possa ser convenientemente estudado. Esse procedimento evitará a perda de cor do material, facilitando seu estudo.

imprescindível que no manuseio da chave, só sejam tomadas decisões, nas duas alternativas oferecidas em cada passo, quando se tiver absoluta certeza do caminho a ser seguido; só assim será possível prosseguir sem erros.

Eventualmente chega-se a uma alternativa que termina com um nome grifado; este é o nome do gênero que se aplica ao material testado, se o caminho foi seguido corretamente. Não termina aí o trabalho. De posse do nome, deverá o estudante procurar em um livro texto, uma descrição ou uma figura do gênero respectivo, a fim de conferir agora todos os detalhes desta descrição com sua planta e verificar se há correspondêncla ou não. Se o resultado for afirmativo então terminou, por hora, o trabalho; se não for afirmativo deverá ele voltar ao início da chave e recomeçar a identificação verificando com cuidado redobrado as alternativas tomadas para evitar a repetição do erro. 
Após certos nomes de gêneros encontrará o estudante, escrito entre parênteses, a palavra parte: isso significa que aquêle gênero figura na chave com duas (ou mais) entradas diversas, a fim de atender ao polimorfismo das espécies incluídas sob a mesma designação genérica.

De um modo geral foram escolhidas alternativas que se opõe, sem deixar dúvidas e em pouquíssimos casos usou-se critério de reprodução como meio de separar um gênero do outro. Evitou-se assim a necessidade de material fértil para se proceder à identíficação.

Recomenda-se ao aluno principiante a consulta dos seguintes livros textos:

1 - F. E. Fritsch. 1935,1945 . The structure and reproduction of the algae. Vol. I: XVII + 791 pp.; Vol. II: XIV + 939 pp. +2 mapas. Cambridge.

2 - A. B. Joly. 1967. Gêneros de algas marinhas da costa atlântica Latino-americana. 461 pp. São Paulo.

Estes livros trazem ilustrações e descrições da totalidade dos gêneros incluídos nesta chave, bem como dão amplas referências bibliográficas, possibiltando ao estudante prosseguir em seus estudos.

\section{CHAVE PARA INDENTIFICAÇÃO DOS GÊNEROS}

1 - Plantas epífitas microscópicas .............. 2

1a - Plantas não epífitas, se epífitas nunca microscópicas 5

2 - Algas com filamentos livres unisseriados ...... 3

$2 a$ - Algas formando crostas disciformes .......... 4

3 - Ramificações abundantes e irregulares, paredes celulares não espessadas ..........ACROCHAETIUM

$3 a$ - Ramificações em geral espaçadas, e, quando abundantes pseudo-dicotômicas (paredes celulares distintamente espessadas) .......... GONIOTRICHUM

4 - Algumas células marginais terminando em V, (em processo de divisão) .......... ERYTHROCLADIA

$4 a$ - Células marginais não terminando em V, dispostas em nitidas fileiras radiais; talo calcificado ........

FOSLIELLA (parte)

5 - Talo constituindo distinta fronde membranácea, larga, sem pedúnculo, de forma regular ou irregular 6

$5 a$ - Talo não membranáceo, ou se o é, então com distinto pedúnculo e de forma regular $\ldots \ldots \ldots \ldots \ldots \ldots, 12$

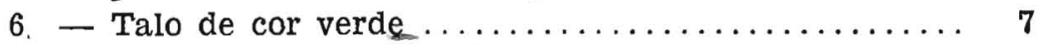

$6 a-$ Talo de cor não verde $\ldots \ldots \ldots \ldots \ldots \ldots \ldots \ldots, 9$ 
7 - Talo firme, células superficiais de vários tamanhos dispostas formando desenhos característicos ......

ANADYOMENE

$7 a$ - Talo flácido, células superficiais sem qualquer disposição

8 - Talo de uma camada de células de espessura

MONOSTROMA

$8 \mathrm{a}$ - Talo de duas camadas de células de espessura . ULVA

9 - Talo de cor marron escura ou clara, às vezes esbranquiçado ........................ 10

9a - Talo de cor vermelha, rósea, cárnea ou arroxeada .. 11

10 - Talo com margens apicais planas limitadas por nitidas células apicais dispostas lado a lado POCOCKIELLA

10a - Talo com margens apicais enroladas ...... PADINA

11 - Talo distintamente gelatinoso ao tacto, de várias camadas de células de espessura

HALYMENIA (parte)

11a - Talo membranoso liso, de apenas uma camada de células de espessura ............... PORPHYRA

12 - Talo constituído de distinto pedúnculo e porção terminal folhácea ...................... 13

12 a - Talo não diferenciado como acima .......... 14

13 - Talo distintamente calcificado, verde esbranquiçado, ou apenas brancacento ............... UDOTEA

$13 a$ - Talo não calcificado, verde escuro ou negro-pardacento .................... AVRAINVILLEA

14 - Plantas essencialmente filamentosas, filamento sempre unisseriados livres, ou cenocíticos ............

14a - Plantas não filamentosas, ou se o são então filamentos nunca são unisseriados, podendo ser cenocíticos, mas então estão densamente trançados, nunca livres

15 - Filamentos verdes, celulares ............. 15

15 a - Filamentos não verdes, se verdes então são cenocíticos

16 - Talo abundantemente ramificado em vários planos, fixo ao substrato por um único ponto . CLADOPHORA

16 a - Talo com nenhuma ou poucas ramificações, se com maior número de ramificações, então com distintas células de fixação aqui e ali

17 - Células de fixação, terminando em discos lobados, plantas formando nítidas almofadas, de côr verde clara

CLADOPHOROPSIS

17a - Só a célula basal do filamento é de fixação, ou se há outras, estas não terminam em discos

18 - Filamentos simples, nunca ramificados

CHAETOMORPHA 
18a - Filamentos distintamente geniculados, com um ou outro ramo rizoidal de uma ou poucas células apenas

19 - Filamentos verdes cenocíticos ............. 20

$19 \mathrm{a}$ - Filamentos não verdes $\ldots \ldots \ldots \ldots \ldots \ldots \ldots \ldots \ldots .22$

20 - Planta com distinto eixo principal e ramos lateral disticos $\ldots \ldots \ldots \ldots \ldots \ldots \ldots \ldots \ldots \ldots \ldots \ldots \ldots$ BRYOPS

$20 a$ - Planta não diferenciada como acima .......... 21

21 - Filamentos regularmente ramificados dicotomicamente, plastos com pirenóides ..... BOODLEOPSIS

21a - Filamentos não ramificados como acima, se entretanto aparentar dicotomia, então plastos sempre sem pirenóides ............. CAULERPA (parte)

22 - Filamentos não vermelhos .............. 23

22 a — Filamentos vermelhos, às vezes côr-de-vinho . . . . 24

23 - Plastos distintamente estrelados, um ou dois por célula ................... BACHELOTIA

23a - Plastos discóides ou quase .... ECTOCARPUS (talvez $\ldots \ldots \ldots \ldots \ldots \ldots \ldots \ldots \ldots \ldots \ldots \ldots \ldots$ GIFFORDIA tb.)

24 - Filamentos abundantemente ramificados ........

CALLITHAMNION

24a - Filamentos nunca ramificados, às vezes em certas porções bi e multisseriados .........BANGIA (parte)

25 - Plantas filamentosas, filamentos bi, tri e multisseriados (às vezes por pseudocasca) ou polissifões ..

25a - Plantas não filamentosas, embora às vezes distintamente formadas por filamentos ou porções cenocíticas variadamente dispostas

26 - Planta crescendo em tufos densos, erectos, de 1 a $3 \mathrm{~cm}$ de altura, de cor marron escura ou negra; crescimento por distinta célula apical e reprodução vegetativa por propágulos com braços ou de âmbito triangular

SPHACELARIA

26a - Plantas não em tufos, nunca há propágulos vegetativos; se em tufos, então são de cor verde ......

27 - Filamentos verdes, em corte transversal mostrando uma região central ôca e uma camada de células na parede .............. ENTEROMORPHA (parte)

27 a - Filamentos vermelhos ou vináceos escuros, não verdes, nuncas ôcos .................... 28

28 - Plantas de âmbito piramidal, com ramos verticilados, delicados ..............WRANGELIA

$28 \mathrm{a}$ - Plantas diferentes $\ldots \ldots \ldots \ldots \ldots \ldots \ldots \ldots \ldots \ldots .29$

29 - Toda a planta, constituída de filamentos com distintos nós e entrenós, estes em parte não corticados, ápices vegetativos em forma de tenaz ..... CERAMIUM 
29a - Filamentos totalmente bi, tri a multisseriados (ou corticados completamente)

30 - Plantas com ápices vegetativo em forma de tenaz, apresentando vertícilos de poucos ou muitos "espinhos" curtos ............... CENTROCERAS

30a - Plantas com ápices não como acima, sem "espinhos"

31 - Filamentos bi e tri-seriados, formando emaranhados

F ALKENBERGIA

31 a - Filamentos plurisseriados (ou polissifões) ...... 32

32 - Filamentos nunca ramificados ..... BANGIA (parte)

$32 \mathrm{a}$ - Filamentos ramificados $\ldots \ldots \ldots \ldots \ldots \ldots \ldots \ldots .33$

33 - Plantas erectas, em geral não diferenciadas em porção prostrada e porção erecta .. POLY IPHONIA

$33 a$ - Plantas distintamente diferenciadas em eixo rastejante e ramos erectos; plantas em geral epifitas ..

HERPOSIPHONIA

34 - Plantas de côr verde ou verde esbranquiçadas caracteristicas. Sempre formadas por filamentos cenocíticos ou porções inteiramente cenocíticas ou terminando em ápices variadamente constituidos por porções celulares; raramente a fronde é tubular

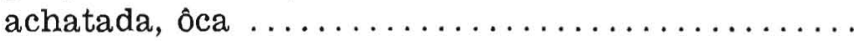

$34 a$ - Plantas não verdes, se são em partes esverdeadas, èsta cor é apenas vista na parte exposta da planta ..

35 - Fronde tubular achatada, ôca, alongada

ENTEROMORPHA (parte)

$35 a$ - Fronde não tubular achatada ............. 36

36 - Fronde globóide, constituída de uma única célula cuja parede limita a fronde (há células rizoidais de fixação) .................... VALONIA (parte)

$36 a$ - Fronde não globoide $\ldots \ldots \ldots \ldots \ldots \ldots \ldots \ldots \ldots . \ldots \ldots$

37 - Plantas crescendo em almofadas, constituídas de células macroscópicas interligadas frouxamente (fixas umas às outras) ..........VALONIA (parte)

37 a - Plantas nunca formando almofadas, se estas existem então são muito densas (duras) com aspecto superficial de favo de abelha ................

38 - Almofadas duras, formadas de células densamente justapostas, com aspecto de favo de abelha ........

DICTYOSPHAERIA

$38 \mathrm{a}$ - Plantas não como acima .................

39 - Plantas constituídas por um distinto pedúnculo que termina no ápice por uma formação capitulisforme variada

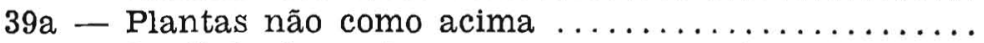

40 - Capítulo formado por um ou alguns (2 ou 3) verti- 
cilos de ramos curtos soldados lateralmente, lembrando no conjunto uma sombrinha ............

$40 \mathrm{a}$ - Capítulo não regularmente verticilado ...........

41 - Paredes dos raios do capítulo, calcificadas, esporos livres no interior do raio .........ACETABULARIA

41a - Interior dos raios do capítulo calcificados e então esporos imersos na massa calcária ..... ACICULARIA

42 - Pedúnculo formado por uma única e longa célula, com parede caracteristicamente anelada

CHAMAEDORIS

42a - Pedúnculo muito mais grosso que acima, não anelado, formado por várias fileiras de filamentos compactados externamente ............. PENICILLUS

43 - Plantas até $3 \mathrm{~cm}$ de altura; talo distintamente clavado ou cilíndrico, com até $2-3 \mathrm{~mm}$ de diâmetro ....

NEOMERIS

$43 a$ - Plantas não como acima ............... 44

44 - Plantas formadas por um eixo central do qual partem ramos laterais por sua vez ramificados até $3 a$., 4a., e mais ordens que se soldam entre si em um plano, pelas extremidades que se tocam, sem entretanto formar um padrão definível de malha STRUVEA

$44 a$ - Plantas não em forma de rede ............. 45

45 - Plantas distintamente diferenciadas em porções rizomatóide e erecta, esta de variadíssima forma . . CAULERPA (parte)

$45 a$ - Plantas não diferenciadas como acima ......... 46

46 - Plantas erectas ou incrustantes, no primeiro caso crescendo isoladas e são ramificadas em geral dicotômicamente com ramos cilíndricos; no segundo caso forram o substrato, sem ramos, erectos; em ambos tipos são formadas por filamentos cenociticos trançados, que se alargam muito na superfície (utrículos) ..................... CODIUM

$46 a$ - Plantas distintamente segmentadas, segmentos achatados, de âmbito arredondado, triangular ou irregular, às vezes soldando-se entre si ... HALIMEDA

47 - Plantas de cor marrom, pärdacentas . . . . . . . 48

$47 a$ - Plantas de cor diversa ................ 55

48 - Talo globóide, liso ou pregueado; ôco, mais tarde enchendo-se com água ............ COLPOMENIA

$48 a$ - Talo não globóide $\ldots \ldots \ldots \ldots \ldots \ldots \ldots \ldots \ldots \ldots .49$

49 - Talo diferenciado em eixos semelhantes a caule, dos quais nascem dois ou três tipos diferentes de ramos laterais, mas achatados, semelhantes a folhas, outros esferoidais, do tamanho de um grão pequeno de ervilha (flutuadores) e outros axilares, cilíndricos finos

Trab. Oseanogr. Univ. Fed. Pe., Recife, 13 271-282, 1972 
50 - Talo em forma de fita estreita ou larga, com distinta nervura central

50 a - Não há nervura central no talo ............. 51

51 - Extremidades das bifurcações crescendo por uma distinta célula apical $\ldots \ldots \ldots \ldots \ldots \ldots \ldots \ldots \ldots \ldots .52$

51 - Crescimento não por uma célula apical ........ 53

52 - Talo em corte transversal mostrando apenas três camadas de células em espessura, duas corticais e uma medular incolor ............... DICTYOTA

$52 \mathrm{a}$ - Talo em corte transversal mostrando em certos pontos mais de três camadas de células em espessura ..

DILOPHUS

53 - Plantas adultas desde a base em forma de fita, dicotomias não frequentes e com desenvolvimento desigual ................. SPATOGLOSSUM

$53 a$ - Plantas adultas nas porções basais, em forma de cordões, só as porções terminais em forma de fita ..

54 - Frondes mostrando em corte transversal que a cada fileira de células medulares correspondem duas células na região cortical .............. ZONARI.A

$54 a$ - Frondes mostrando em corte transversal que a cada fileira de células medulares correspondem mais de duas células na região cortical .......STYPOPODIUM

55 - Ápices em crescimento com uma distinta célula apical (às vezes o ápice dos ramos está no fundo de pequena depressão)

$55 a$ - Ápices em crescimento sem célula apical evidente 84

56 - Talo distintamente segmentado, isto é com constrições regularmente espaçadas .............. 57

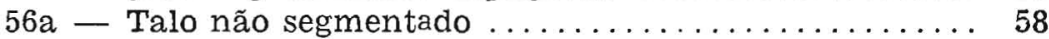

57 - Talo folháceo, com distinta nervura central .....

CALOGLOSSA

$57 a$ - Talo de consistência carnosa, de 1 a $3 \mathrm{~mm}$ de espessura, sem nervura ............. CATENELLA

58 - Plantas mostrando à lupa ou ao microscópio terem estrutura em rede, mais ou menos densa ........ 59

58 a - Plantas não reticuladas .................. 61

59 - Talo distintamente achatado, de consistência de feltro, de cor parda-avermelhada .... HALOPLEGMA

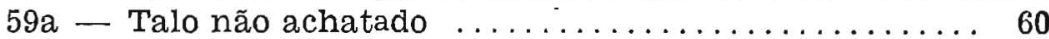

60 - Talo pouco ramificado, de secção quadrangular nítida .................... DICTYURUS

60 a - Talo ramificado, ramos cilindricos ...... THURETIA

61 - Plantas com eixo principal distinto, ramificação 
distica, podendo repetir-se nos ramos laterais, em geral em um só plano ................... 62

61 - Ramificação não dística ................. 71

62 - Ramos de última ordem, organizado em nó e entrenó; os nós distintamente corticados, deixando o entrenó unicelular a descoberto entre nós sucessivos

SPYRIDIA

$62 a$ - Ramos de última ordem não como acima ....... 63

63 - Plantas duras e ásperas ao tacto ........... 54

$63 a$ - Plantas mais suaves ao tacto .............. 65

64 - Plantas crescendo em almofadas densas, na parte alta dos arrecifes .............. GELIDIELLA

64 a - Plantas crescendo isoladamente, nunca na parte alta dos arrecifes ........... BRYOTHAMNION (parte)

65 - Eixos e ramos principais, distintamente alargados em forma de fita .................... 66

$65 a$ - Eixos ou ramos principais, não alargados em forma de fita

66 - Extremidades em crescimento terminando em ponta ENANTIOCLADIA

66a - Extremidades em crescimento distintamente arredondadas

67 - Talo em corte transversal, mostrando nos bordos apenas duas camadas de células em espessura ....

AMANSIA

67a - Talo em corte transversal, de várias camadas de células em espessura .............. VIDALIA

RQ - Ramos laterais de última ordem (ver na lupa) sempre saindo em ângulo, muito regularmente; em geral só há ramos de primeira orđem ... PTEROSIPHONIA

68 a - Ramos laterais e última ordem não como acima, em geral há ramos de $2 a ., 3 a ., 4 a$. ordens (ou mais às vezes)

69 - Plantas de cor negra ou pardacentas . BOSTRYCHIA

69 a - Plantas de cor vermelha ............... 70

70 - Eixos em corte transversal com muitos rizóides internos (rizines), de paredes grossas, de preferência na região medular

PTEROCLADIA

70a - Eixos em corte transversal com rizóides internos (rizines), de paredes grossas, de prefência na região cortical ..................... GELIDIUM

71 - Plantas em geral epífitas, com muitos ramos terminando em ganchos ............ HYPNEA (parte)

$71 \mathrm{a}$ - Plantas sem ganchos $\ldots \ldots \ldots \ldots \ldots \ldots \ldots \ldots \ldots .72$

72 - Eixos principais variadamente revestidos de ramos curtos espinescentes

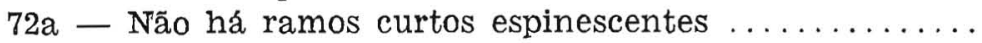
76

73 - Ramos espinescentes, como que formando pequenos

Trab. Oceanogr. Univ. Fed. Pe., Recife, 13 271-282, 1972 
$73 a$ - Ramos espinescentes simples, isolados

74 - Ramos espinescentes, dispostos formando 3 fileiras longitudinais evidentes ... BRYOTHAMNION (parte)

$74 a$ - Ramos espinescentes, dispostos espiraladamente não formando 3 fileiras

75 - Plantas vermelhas, com $20-25 \mathrm{~cm}$ de altura, ramos espinescentes superiores com pelos hialinos ramificados na base, crescendo isoladamente

WRIGHTIELLA

75a - Plantas pardacentas, com até $7-8 \mathrm{~cm}$ de altura, crescendo em tufos .............. BRYOCLADIA

76 - Eixos principais às vêzes somente próximo ao ápice revestidos de ramos curtos, muito delicados, flácidos quase desaparecendo ao se remover a planta da

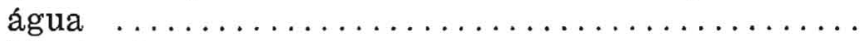

$76 a$ - Eixos não como acima $\ldots \ldots \ldots \ldots \ldots \ldots \ldots \ldots$

77 - Cada segmetno do eixo principal, transportando um râmulo lateral obrigatoriamente ......... DAYSA

77 a - Nem todos os segmentos do eixo principal produzem râmulos ................. HETEROSIPHONIA

78 - Eixos principais, transportando ramos laterais curtos, em geral arredondados no ápice que na maioria das vezes é imerso em uma pequena depressão (ver

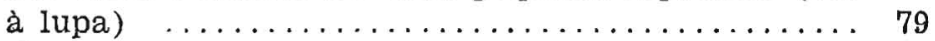

$78 \mathrm{a}$ - Ápices evidentes, não imersos em depressão ..... 80

79 - Eixos em corte transversal com 5 células pericentrais

CHONDRIA

79a - Eixos em corte transversal com mais de 5 células pericentrais .................. LAURENCIA

80 - Plantas com eixos principais muito pouco ramificados, de cor negra ........... PROTOKUETZINGIA

$80 a$ - Plantas regularmente ramificadas, nunca negras . . 81

81 - Plantas espessas, cilindricas, ou alargadas no ápice pouco ramificadas, de consistência de feltro duro, com 0,5 a $1 \mathrm{~cm}$ de largura geralmente densamente recobertas de epífitas de vários tipos ..... DIGENEA

$81 a$ - Plantas não grossas como acima ........... 82

82 - Eixos ôcos (ou quasi) em corte transversal

AGARDHIELLA

$82 \mathrm{a}$ - Eixos sólidos em corte transversal .......... 83

83 - Eixos em corte transversal com uma pequena célula central envolvida por 5 grandes células que ocupam mais da metade do diâmetro do corte ........

HYPNEA (parte)

$83 a$ - Organização diversa do corte transversal ao eixo . .

OCHTODES 
84 - Plantas com impregnação de carbonato de cálcio (testar com $\mathrm{HCl}$ diluído) $\ldots \ldots \ldots \ldots \ldots \ldots \ldots \ldots . \ldots \ldots$

$84 a$ - Plantas não calcificadas ............... 94

85 - Talo crostoso, revestindo o substrato, as vezes formando concreções isoladas que podem ser ramificadas $\ldots \ldots \ldots \ldots \ldots \ldots \ldots \ldots \ldots \ldots \ldots \ldots$

$85 a$ - Talo não crostoso, erecto ou formando almofadas . 89

86 - Talo distintamente vermelho, às vezes vermelho escuro até cor-de-vinho ............. PEYSSONELIA

86 - Talo róseo, ou vermelho arroxeado ........... 87

87 - Planta epífitas em algas maiores, formando crostas delicadas, de uma só camada de células em espessura nas porções vegetativas .......FOSLIELLA (parte)

87a - Plantas muito mais grossas, sempre de várias camadas de células em espessura ............ 88

88 - Conceptáculos tetraspóricos com um único poro cen-

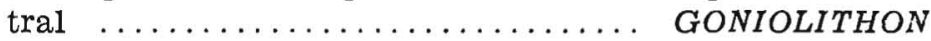

88 a - Conceptáculos tetraspóricos com vários poros ....

LITHOTHAMNIUM

89 - Talo ramificado disticamente ........ CORALLINA

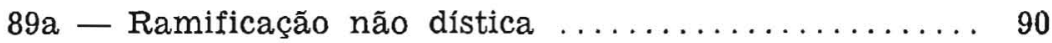

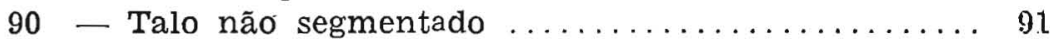

$90 a$ - Talo segmentado $\ldots \ldots \ldots \ldots \ldots \ldots \ldots \ldots \ldots \ldots .92$

91 - Talo em forma de fita repetidamente ramificado dicotomicamente. Epiderme continua

GALAXAURA (parte)

91a - Talo com ramos cilindricos, ramificados dicotomicamente, mas esparsamente; não há epiderme continua

LIAGORA

92 - Segmentos ôcos .......... GALAXAURA (parte)

$92 \mathrm{a}$ - Segmentos sólidos $\ldots \ldots \ldots \ldots \ldots \ldots \ldots \ldots \ldots .93$

93 - Talo com segmento cilindricos, ramificados dicotomicamente, conceptáculo apicais, um por ségmento

JANIA

$93 a$ - Talo com segmentos em geral comprimidos, ramificação irregular, conceptáculos espalhados na superfície do segmento fértil, vários por segmento ......

AMPHIROA

94 - Talo distintamente achatado, em forma de fita, não de folha larga ...................... 95

$94 \mathrm{a}$ - Talo não em forma de fita ............... 98

95 - Talo irregular e abundantemente verrucoso, ramificado das margens ............ EUCHEUMA (parte)

$95 a \ldots$ Talo não verrucoso $\ldots \ldots \ldots \ldots \ldots \ldots \ldots \ldots \ldots \ldots$

96 - Talo em corte transversal, sólido, isto é, praticamente não há espaços entre as células medulares, estas têm a mesma forma das células mais externas, 
$96 a$ - Talo em corte transversal com muita mucilagem ou espaços entre as células da região central; esta é formada de células e filamentos; as células da região medular ou subcortical são distinatmente estrela-

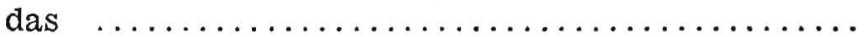

97 - Plantas escorregadias ao tacto, de cor esverdeada GRATELOUPIA

$97 a$ - Plantas rígidas mais ou menos ásperas ao tacto ...

CRYPTONEMIA

98 - Talo cilíndrico de consistência de gelatina mole, repetidamente ramificado dicotomicamente ....... HALYMENIA (parte)

98 - Talo não flácido como acima, ramificação não dicotomica regular ....................

99 - Talo diferenciado em eixos cilíndricos que transportam ramos curtos globóides, como cachos de pequenas uvas, densas ou não .......... BOTRYOCLADIA

99 a - Talo sem a diferenciação acima . . . . . . . . . . . 100

100 - Eixos "de consistência gelatino às vezes terminando em ganchos, ôcos, distintamente separado por zonas transversais mais escuras ........... CHAMPIA

100a - Eixos não zonados, nunca terminando em ganchos . 101

101 - Plantas de cor negra, formando tufos baixos, densos, de poucos cm de altura; ramificação di a politômica GYMNOGONGRUS

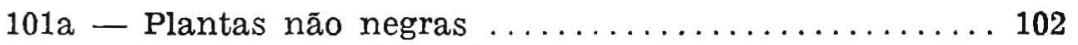

102 - Ramificação de certos eixos, distintamente unllateral, aproximada (em forma de pente)

\section{GRACILARIOPSIS}

$102 a$ - Ramifícação não como acima ............. 103

103 - Plantas crescendo em tufos, com porções rastejantes cilíndricas e erectas; talo duro, de consistêncía de arame, de cor verde-negra ..........GELIDIOPSIS

$103 a$ - Plantas sem diferenclação em porções rastejantes e erectas, não de cor negra ............... 10 \&

104 - Talo verrucoso, às vezes melhor visfivel nas porções mais velhas .............. EUCHEUMA (parte) 104a - Talo não verrucoso ......... GRACILARIA (parte)

\section{ABSTRACT}

This paper presents a dichotomic simplified key for students use as an aid to the identification of the 92 genera of inter-tidal marine algae found on or nearby Recife, State of Pernambuco, Brazil.

A short introduction leads the beginner on the procedures to follow in order to best use the key. 